\title{
IBM BAGI SISWA KELAS XI SMK TEKNIK KENDERAAN RINGAN DI SMK NEGERI I SEI RAMPAH KABUPATEN SERDANG BEDAGAI
}

\section{IBM For Class Xi Students Of Lightweight Vocational Engineering In State Vocational School I Sei Rampah Serdang Bedagai District}

\section{Junaidi}

\section{Din Aswan Amran Ritonga ${ }^{2}$}

*1,2 Program Studi Teknik Mesin, Fakultas Teknik dan Komputer, Universitas Harapan Medan

*email:

junaidi.unhar@harapan.ac.id

\section{Kata Kunci:}

Pelatihan

Uji Kompetensi

Kegagalan

Teknik Kenderaan Ringan

\section{Keywords:}

\section{Training}

Competency Test

Failure

Light Vehicle Technique

\begin{abstract}
Abstrak
SMK Negeri I Sei Rampah Kabupaten Serdang Bedagai setiap tahunnya mengadakan Ujian Kompetensi untuk kelas XII SMK Kenderaan Ringan ,pada waktu sebelum melakukan Ujian Nasional.Untuk Setiap tahunnya hampir 90\% mendapat kegagalan dalam Ujian Kompetensi yang dilakukan oleh para siswa tersebut.Oleh sebab itu kami dari staf Pengajar Fakultas Teknik dan Komputer mengabdi ke SMK ini untuk mengadakan Pelatihan Uji Kompetensi bagi Siswa Kelas XI ,agar jangan sampai gagal pada saat Mereka nantinya di kelas XII,untuk melaksanakan ujian kompetensi .Adapun Pelaksanaan pelatihan kompetensi adalah: Pelatihahan uji kompetensi Tune up, Sistem Kelistrikan ,Sistem Kemudi ,Over Hole Engine dan chasis.
\end{abstract}

\begin{abstract}
State Vocational School I Sei Rampah Serdang Bedagai Regency annually holds Competency Exams for Class XII Lightweight Vocational School, prior to conducting the National Examination. Every year almost $90 \%$ fail in the Competency Exams conducted by these students. Therefore we are from Faculty of Engineering and Computer teaching staff serve this Vocational School to hold Competency Test Training for Class XI Students, so as not to fail when they later in class XII, to carry out competency tests. As for the implementation of competency training are: Tune up competency test training, Electricity, Steering System, Over Hole Engine and chassis.
\end{abstract}




\section{PENDAHULUAN}

Perubahan teknologi yang sangat cepat, memaksa organisasi untuk menyesuaikan diri dengan lingkungan usahanya. Perubahan tersebut telah menggeser fungsi-fungsi manajeman sumber daya manusia yang selama ini hanya dianggap sebagai kegiatan administrasi, menjadi suat.Saat ini manajeman Sumber Daya Manusia (SDM) berubah dan fungsi spesialisasi yang berdiri sendiri menjadi suatu hal yang sangat strategis. SDM menjadi fungsi yang terintegrasi dengan seluruh fungsi lainnya di dalam organisasi, untuk bersama-sama mencapai sasaran yang sudah ditetapkan serta memiliki fungsi perencanaan yang sangat strategik dalam organisasi, dengan kata lain fungsi SDM lama menjadi lebih bersifat strategik. Oleh karenanya manajemen SDM mempunyai kewajiban untuk: memahami perubahan yang semakin komplek yang selalu terjadi di lingkungan bisnis, harus mengantisipasi perubahan teknologi, pasar, persaingan yang mulai memasuki bisnis akibat informasi yang berkembang cepat(Junaidi, Jumadi, Mhd.Akhir, Mhd.Idris, Haida, jamiah, darmawati, 20I5). Perubahan paradigma dari manajemen SDM tersebut telah memberikan fokus yang berbeda dalam melaksanakan fungsinya di dalam organisasi.Ada kecenderungan untuk mengakui pentingnya SDM dalam organisasi dan pemusatan perhatian pada kontribusi fungsi SDM bagi keberhasilan pencapaian tujuan strategi organisasi. Hal ini dapat dilakukan organisasi dengan mengintegrasikan pembuatan keputusan strateginya dengan fungsi-fungsi SDM maka akan semakin besar kesempatan untuk memperoleh keberhasilan. Salah satu bagian penting adalah bagaimana mengelola siswa agar bisa mengeluarkan kemampuan terbaiknya. Untuk itu siswa haruslah dilatih, dikembangkan, diberi posisi yang sesuai dengan ilmu dan keterampilannya. Secara umum, kebutuhan pelatihan datang dari masalah kinerja (lack of performance) yang disebabkan oleh kurangnya kompetensi pegawai (lack of competency) (Ahmad Yanie, 2016). Dalam prakteknya, organisasi selalu memberikan pelatihan kepada siswanya tetapi antara dana yang dihabiskan dan hasil yang dicapai tidak begitu seimbang sehingga timbul pemikiran program pelatihan tersebut hanya buang-buang waktu, tenaga dan pemborosan uang organisasi saja.Mengapa bisa terjadi demikian, tidak selamanya masalah kinerja disebabkan oleh kurangnya kompetensi tetapi juga bisa disebabkan factor system dan factor lain dalam diri manusia. Dari sisi manusia masalah kinerja dapat disebabkan masalah kepemimpinan, motivasi, disiplin dan lain-lain. Dari sisi system, masalah kinerja bisa saja disebabkan oleh peralatan, organisasi, teknologi dan sebagainya. Untuk itu penilaian kebutuhan harus melihat apakah masalah kesenjangan (GAP) tersebut benar-benar disebabkan kurangnya pengetahuan, keterampilan atau hal lain. Pertanyaan-pertanyaan berupa; Bagaimana pelatihan bisa memberikan kontribusi terhadap profitabilitas organisasi? Siapa saja yang menjadi target pelatihan? Pelatihan apa saja yang perlu dilakukan dan bagaimana hasilnya? Menjadi penting agar kita mengetahui program yang telah dirancang/dilaksanakan telah berjalan sukses atau tidak. Mungkin saja setelah selesai mengikuti pelatihan, pegawai tidak bisa menerapkan knowledge, skill and attitude yang didapatnya karena sistem tidak memungkinkan. Hal ini mengisyaratkan bahwa dalam mengembangkan kinerja organisasi pelatihan tidak bisa berjalan sendiri (Junaidi, Jumadi, Mhd.Akhir, Mhd.Idris, Haida, jamiah, darmawati, 20I5). Sosialisasasi Pelatihan Uji kompetensi ini akan dilaksanakan di SMK Negeri I Sei rampah Kabupaten serdang Bedagai Profinsi Sumatera Utara. Siswa yang akan dilatih adalah siswa kelas $\mathrm{XI}$, dari SMK Jurusan Teknik Kenderaan Ringan (TKR) Negeri I Sei Rampah. Kepala sekolah bapak Drs.Surianto sudah I4 tahun menjabat Kepala Sekolah.

$\mathrm{Hal}$ ini berdasarkan dengan Peraturan Pemerintah (PP) Nomor 19 Tahun 2005 tentang Badan Standar Nasional Pendidikan (BSNP) (Indonesia, 2005) ditegaskan bahwa tenaga pendidik harus memiliki kompetensi sebagai agen pembelajaran, sehat jasmani 
dan rohani, pada jenjang pendidikan dasar dan menengah, serta pendidikan anak usia dini (Siswati Saragil et al., 2020). Arahan normatif tersebut yang menyatakan bahwa tenaga pendidik dalam hal ini sebagai agen pembelajaran menunjukkan pada harapan bahwa guru merupakan pihak pertama yang paling bertanggung jawab dalam pentransferan ilmu pengetahuan kepada peserta didik (Windartol* et al., n.d.). Dalam sebuah penelitian yang dilakukan oleh Lia Christiyanti (Univ.SanataDharma,Yogyakarta, 2017) dikatakan bahwa : Keterampilan keahlian dapat diperoleh melalui sebuah pelatihan (Umar Hamdan Nasution I \& Iskandar2, 2020). Pelatihan merupakan bagian dari pendidikan yang menyangkut proses belajar untuk memperoleh dan meningkatkan keterampilan diluar sistem pendidikan yang berlaku, dalam waktu yang relatif singkat dan dengan metode yang lebih mengutamakan praktek dari pada teori (Lukman Hakim Siregarl \& Junaidi2, 2020).

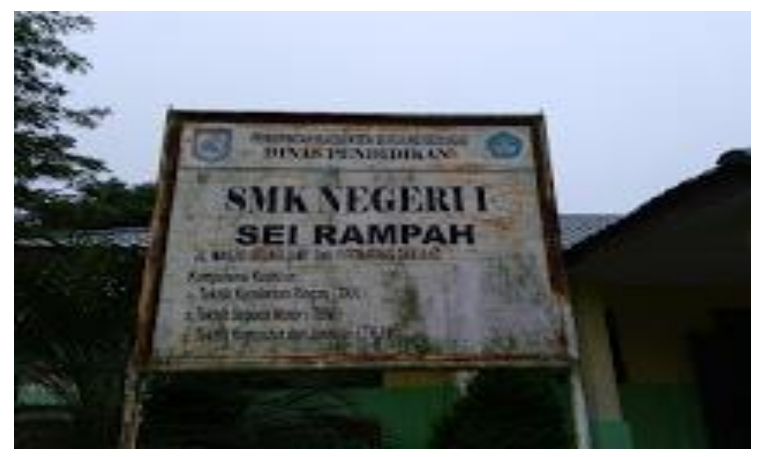

Gambar I. Papan nama SMK. Negeri I Sei Rampah

\section{METODOLOGI}

Pelaksanan pengabdian masyarakat ini dilaksanakan selama bulan Desember 2019. Kegiatan ini dilaksanakan dalam dua hari, mulai jam 08.00-12.00 WIB (sesi Pertama), I3.00- 17.00 WIB (sesi kedua), pada 20 Desember 2019, Lokasi pengabdian bertempat di Ruang Praktek Teknik Kenderaan Ringan (TKR) SMK Negeri I Sei. Rampah Kabupaten Serdang Bedagai. Peserta kegiatan adalah Siswa SMK Negeri I Teknik Kenderaan Ringan yang berjumlah 40 orang yang mewakili. Materi yang disampaikan dalam kegiatan ini adalah tentang pembelajaran praktek kompetensi.
Metode penyampaian dengan cara presentasi dan praktek yang dilakukan oleh dosen dan mahasiswa prodi Teknik Mesin. Berikut adalah aktivitas serta jadwal pengabdian disajikan dalam Tabel I:

\begin{tabular}{|c|c|c|c|}
\hline Tanggal & Waktu & Materi & Penyaji \\
\hline \multirow{11}{*}{$\begin{array}{l}20 \\
\text { Februari } \\
019\end{array}$} & $\begin{array}{l}09.00- \\
09.10 \mathrm{Wib}\end{array}$ & PRE TES & TIM \\
\hline & $\begin{array}{l}09.10- \\
12.00\end{array}$ & $\begin{array}{ll}\text { a. } & \text { Sistim Kelistrikan } \\
\text { b. } & \text { Pada Mobil. } \\
\text { c. } & \text { Sistim Pengapian Bahan } \\
& \text { Bakar } \\
\text { d. } & \text { Sistim } \\
& \text { Pendinginan } \\
\text { e. } & \text { Sistim Pelumasan } \\
\text { f. } & \text { Sistim Pengisian }\end{array}$ & $\begin{array}{l}\text { Ir. Junaidi, } \\
\text { Spd, MM, } \\
\text { MT }\end{array}$ \\
\hline & $\begin{array}{l}13.00- \\
17.00\end{array}$ & $\begin{array}{ll}\text { a. } & \text { Praktek Tune up } \\
\text { b. } & \text { Praktek,sistim } \\
& \text { Penerangan } \\
\text { lampu mobil }\end{array}$ & $\begin{array}{l}\text { Ir. Junaidi, } \\
\text { Spd, MM, } \\
\text { MT }\end{array}$ \\
\hline & & $\begin{array}{ll}\text { c. Praktek,Sistim } \\
\text { Pengapian. } \\
\text { d. Praktek Sistim } \\
\text { Pengisian }\end{array}$ & $\begin{array}{l}\text { Din Aswan } \\
\text { Amran } \\
\text { Ritonga, ST, } \\
\text { MT. }\end{array}$ \\
\hline & & e. Praktek,Sistim & \\
\hline & & Praktek,Sistem & \\
\hline & & Pendinginan. & \\
\hline & & $\begin{array}{ll}\text { g. } & \text { Praktek Sistem } \\
\text { Kemudi }\end{array}$ & \\
\hline & & h. Praktek,Sistem & \\
\hline & & Pemindah & \\
\hline & & Tenaga. & \\
\hline
\end{tabular}

Metode yang dilakukan adalah:

I) Penyuluhan atau Sosialisasi

Sosialisasi adalah proses penanaman atau transfer kebiasaan atau nilai dan aturan dari satu generasi ke generasi lainnya dalam sebuah kelompok atau masyarakat. Sejumlah sosiolog menyebut sosialisasi sebagai teori mengenai peranan (role theory). Karena dalam proses sosialisasi diajarkan peranperan yang harus dijalankan oleh individu. Sosialisasi adalah proses membangun atau menanamkan nilainilai kelompok pada diri seseorang.

2) Diskusi Interaktif

Diskusi adalah sebuah interaksi komunikasi antara dua orang atau lebih/ kelompok. Biasanya komunikasi antara mereka/ kelompok tersebut 
berupa salah satu ilmu atau pengetahuan dasar yang akhirnya akan memberikan rasa pemahaman yang baik dan benar. Diskusi bisa berupa apa saja yang awalnya disebut topik. Dari topik inilah diskusi berkembang dan diperbincangkan yang pada akhirnya akan menghasilkan suatu pemahaman dari topik tersebut.

3) Pelatihan

Pelatihan yang diberikan adalah tentang bagaimana meracik kopi dengan menggunakan peralatan yang lebih baik untuk menghasilkan pembelajaran yang bevariasi dan lebih enak. Pada kegiatan pengabdian ditetapkan yang menjadi fokus ialah Pelatihan uji kompetensi di Jurusan Teknik Kenderaan Ringan (TKR) di SMK. Negeri I Kecamatan Sei Rampah Kabupaten Serdang Bedagai.

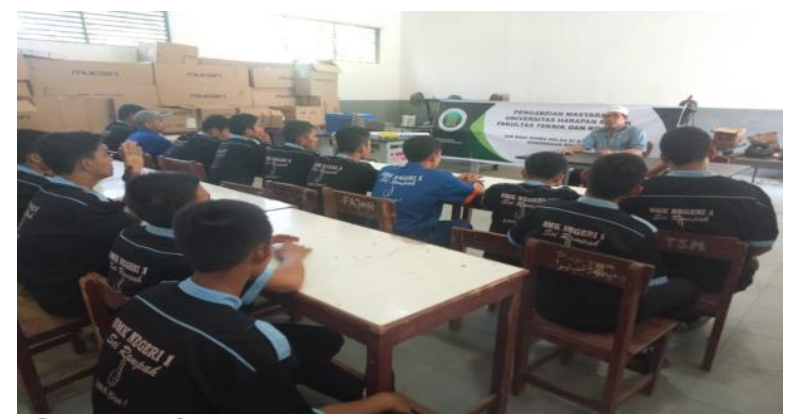

Gambar 2. Pelaksanaan Pelatihan Kompetensi siswa SMK TKR

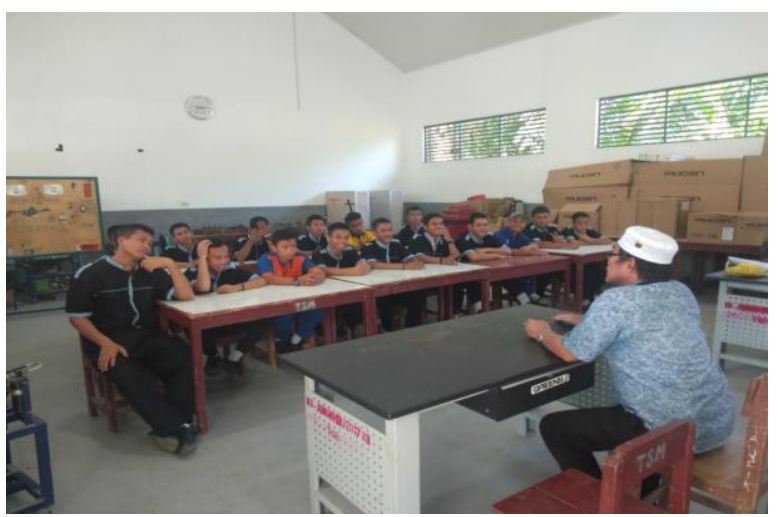

Gambar 3. Pelaksanaan Pelatihan Kompetensi siswa SMK TKR

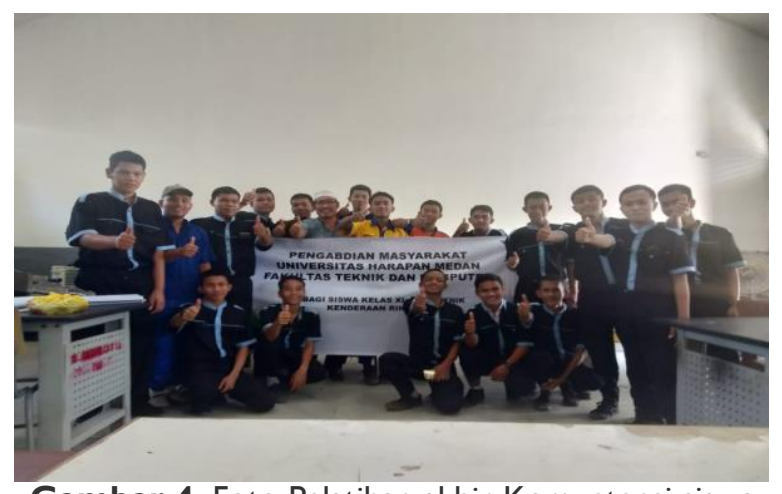

Gambar 4. Foto Pelatihan akhir Kompetensi siswa SMK TKR dengan dosen pemateri

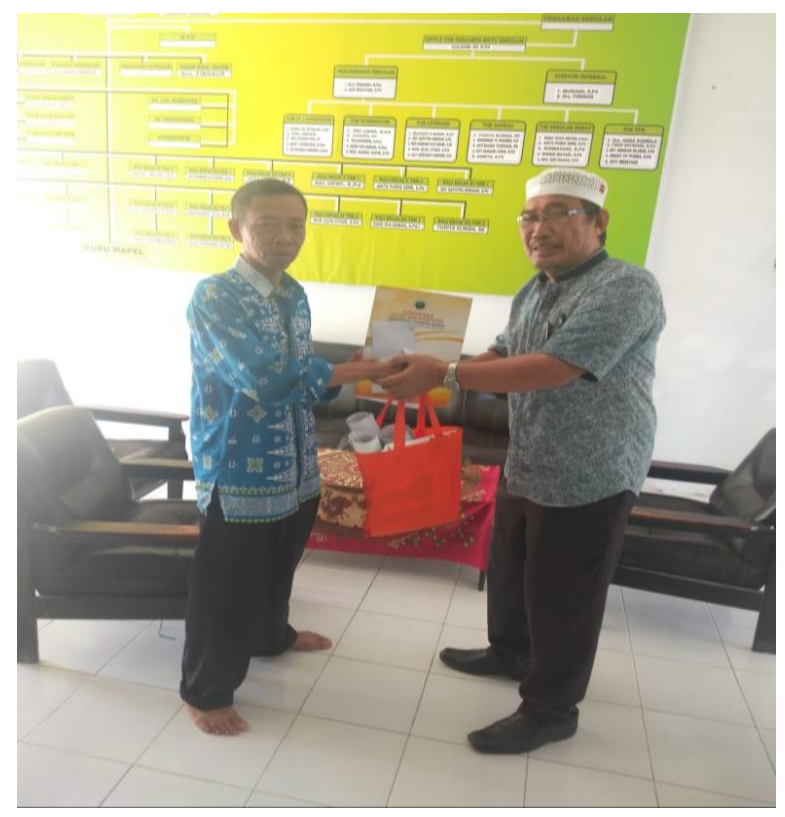

Gambar 5. Ucapan dan salam Terimakasih antara

Dosen Pemateri dengan Kepala Sekolah SMK Negeri I Sei. Rampah

\section{HASIL DAN PEMBAHASAN}

Berikut adalah hasil pengamatan untuk 40 orang siswa berdasarkan

Tabel I. Hasil Pengamatan untuk 40 Orang siswa

\begin{tabular}{cccccccccc}
\hline No & X1 & X2 & X3 & X4 & X5 & X6 & X7 & X8 & X9 \\
\hline 1 & 20 & 4 & 2 & 4 & 2 & 2 & 2 & 2 & 2 \\
2 & 25 & 5 & 3 & 5 & 3 & 3 & 2 & 2 & 2 \\
3 & 30 & 5 & 4 & 5 & 4 & 3 & 3 & 3 & 3 \\
4 & 35 & 6 & 5 & 5 & 4 & 3 & 4 & 4 & 4 \\
\hline
\end{tabular}

Keterangan:

XI : Praktek Unggulan (Orang)

$\times 2$ : Tune Up

X3 : Sistem Penerangan

$\times 4$ : Sistem Pengapian

$\times 5$ : Sistim Pengisian

X6 : Sistim Pendinginan 
X7 : Sistim Pelumasan

X8 : Sistim Kemudi

X9 : Sistim P.Tenaga

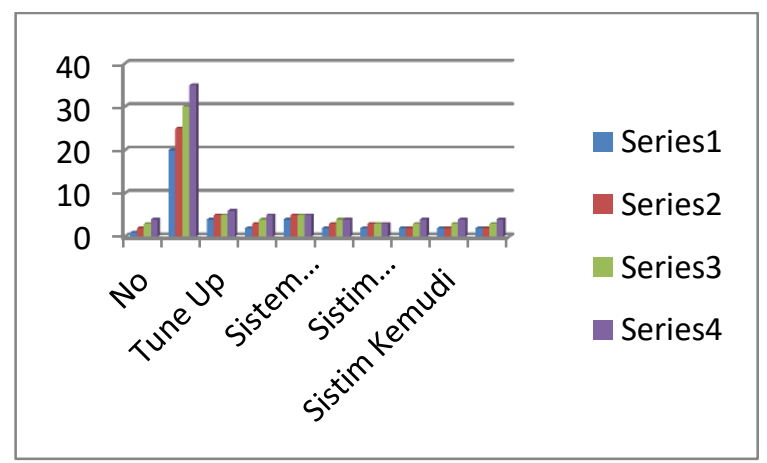

Gambar 5. Grafik Hasil Pengabdian

\section{KESIMPULAN}

Dari hasil yang kita peroleh bahwa siswa yang melakukan pelatihan ini paling banyang unggul 35 Orang yang mempunyai minat terkecil adalah 20 Orang. Selanjutnya yang kurang minat materi yang dilaksanakan adalah materi sistem Kemudi dan sistem Pemindahan Tenaga. Sedangkan yag paling banyak minatnya adalah Tune Up. yang menengah adalah sistem penerangan,sistem pengapian, pendinginan dan pelumasan.

\section{REFERENSI}

Ahmad Yanie, J. (2016). Pelatihan Aplikasi Penggunaan matlab untuk meningkatkan Pengetahuan Guru Mate Matika.

Junaidi, Jumadi, Mhd.Akhir, Mhd.Idris, Haida, jamiah, darmawati, S. nst. (20I5). Pelatihan Penilaian Prestasi Kerja Terhadap Promosi Pegawai Pada Kantor Kepala Desa Mata Pao Kecamatan Teluk Mengkudu Kabupaten Serdang Bedagai. In Laporan PenGABDIAN (p. 35). P4M STTH.

Lukman Hakim Siregar I, L. D., \& Junaidi2, S. (2020). Pelatihan Perencanan Bisnis Jasa Sewa Kapal Motor "Mancing Mania" Di Kelurahan Nelayan Indah Kecamatan Medan Labuhan Kota Medan. Reswara: Jurnal Pengabdian Kepada Masyarakat, I(I), 24-33.

Siswati Saragil, K., Sinaga2, Budiman Purba3, M., \& Batoebara4, U. (2020). Pelatihan Peracikan Kopi Untuk Meningkatkan Minat Wirausaha Masyarakat Desa Rugemuk Kabupaten Deli Serdang. RESWARA: Jurnal Pengabdian Kepada Masyarakat, I(I), 34-37.
Umar Hamdan Nasution I, E., \& Iskandar2, C. Z. (2020). Pkm Pelatihan Perencanaan Bisnis Makanan Khas Laut Di Kelurahan Nelayan Indah. RESWARA: Jurnal Pengabdian Kepada Masyarakat, $I(I)$.

Windartol*, A. P., Parlina2, I., \& Wanto3, A. (n.d.). Pelatihan Guru-Guru Paud "Melek" Teknologi Kabupaten Simalungun. Jurnal TUNAS: Jurnal Ilmiah Pengabdian Kepada Masyarakat, I(I), I-6. https://doi.org/http://dx.doi.org//0.30645/.vlil . 